Pela revolução na periferia - notas introdutórias sobre a teoria do desenvolvimento desigual e combinado de Leon Trotsky. Revista Ensaios, vol. 14, jan-jun de 2019.

\title{
Pela revolução na periferia - notas introdutórias sobre a teoria do desenvolvimento desigual e combinado de Leon Trotsky
}

Matheus de Carvalho Barros ${ }^{1}$

Resumo: O presente trabalho tem por objetivo analisar de forma introdutória a teoria do desenvolvimento desigual e combinado de Leon Trotsky, considerada por alguns de seus interpretes a principal contribuição teórica do revolucionário russo ao marxismo. A tese desenvolvida por Trotsky não é apenas uma reflexão sobre as contradições econômicas e sociais de países de capitalismo periférico. É também uma das principais tentativas teóricas de rompimento com o evolucionismo e mecanicismo característicos do marxismo da Segunda internacional. Os estudos sobre as particularidades do desenvolvimento social russo produzidos por Trotsky serviram de base não apenas para a construção de uma teoria da revolução que estivesse assentada sobre a realidade concreta da Rússia, mas também estava carregada implicitamente de uma significação mais abrangente, aplicável ao conjunto de diversas formações sociais situadas na periferia do capitalismo. Portanto, a finalidade deste artigo é examinar de forma sucinta os principais pontos da teoria do desenvolvimento desigual e combinado, considerando-a indispensável para qualquer perspectiva de transformação social.

Palavras-chave: Leon Trotsky; Teoria do desenvolvimento desigual e combinado; Marxismo

\section{By the revolution on the pheriphery - introductory notes to Leon Trotsky uneven and combined development theory}

Abstract: This work's object is analyzing in na introductory way Leon Trotsky Uneven and Combined Development Theory, considered by some of its interpreters the main theoretical contribution of the russian revolutionary to Marxism. Trotsky`s studies about Rusian`s social development particularities erved as a basis not only for the revolution`s theory construction based on Russia`s concrete reality but they were also implicity charged with a broader meaning appçicable to a set of all many social formations located on capitalism's periphery. Therefore, this article finality is to briefly examine the main points of the Uneven and Combined Development Theory, concluding that it's indispensable for any social transformation perspective.

Keywords: Leon Trotsky; Uneven and Combined Developmente Theory; Marxism

\footnotetext{
1 Universidade Federal Fluminense (UFF), Graduação em Ciências Sociais, Niterói, RJ, Brasil. matheuskdp2@hotmail.com.
} 
Pela revolução na periferia - notas introdutórias sobre a teoria do desenvolvimento desigual e combinado de Leon Trotsky. Revista Ensaios, vol. 14, jan-jun de 2019.

É difícil dimensionar a importância política e intelectual de Leon Trotsky (18791940). Presidente do Soviete de Petrogrado nas revoluções de 1905 e 1917, organizador do exército vermelho, líder da oposição a Stalin na Rússia e fundador da Quarta Internacional, Leon Trotsky se configura como um dos personagens mais importantes da história do movimento socialista, e da história do século XX como um todo (BIANCHI, 2005).

Através dos seus estudos e análises das particularidades do desenvolvimento social da Rússia, Trotsky produz o que pode ser considerado uma de suas maiores contribuições teóricas ao movimento socialista. Refiro-me aqui à teoria do desenvolvimento desigual e combinado, considerada por Ernst Mandel como a principal colaboração de Leon Trotsky a teoria marxista (LOWY, 1998).

A teoria desenvolvida pelo revolucionário russo não é apenas uma reflexão das contradições econômicas e sociais dos países de capitalismo periférico dominados pelo imperialismo. É também, segundo Michael Lowy (1998), uma das tentativas mais significativas de romper com o evolucionismo, a ideologia do progresso linear e o mecanicismo característicos do marxismo da Segunda Internacional. Segundo Baruch Knei-Paz, a teoria do desenvolvimento desigual e combinado é "a primeira e mais original adaptação da teoria e dos instrumentos conceituais do marxismo à analise da mudança nas sociedades pré-capitalistas subdesenvolvidas” (KENEI-PAZ, 1985, p. 164).

Alvaro Bianchi no texto $O$ primado da política: revolução permanente $e$ transição destaca que os primeiros esboços dessa teoria encontram-se em 1905 e Balanços e perspectivas, as duas obras que Leon Trotsky consagrou a análise da revolução russa de 1905. Segundo Bianchi (2001), o ponto de partida dos dois textos é a análise do capitalismo russo e suas profundas relações com o capitalismo europeu. Nesses dois ensaios, como destaca Lowy (1998), a expressão desenvolvimento desigual e combinado ainda não aparece. Mas questões centrais da teoria estão já esboçadas.

Diferentemente de Lenin que analisava o desenvolvimento do capitalismo russo a partir das contradições internas, Trotsky abordava a questão analisando a inserção da economia russa no sistema capitalista mundial. Nesse sentido, "a formação social russa 
Pela revolução na periferia - notas introdutórias sobre a teoria do desenvolvimento desigual e combinado de Leon Trotsky. Revista Ensaios, vol. 14, jan-jun de 2019.

era tomada como um subconjunto periférico do capitalismo mundial, que formava, de forma determinante, sua estrutura econômica e social (LOWY, 1998, p. 74). Trotsky analisa que:

O capitalismo não se desenvolveu na Rússia a partir do sistema artesanal. Ele realizou a conquista da Rússia tendo, atrás de si, o desenvolvimento econômico de toda a Europa (...) Reduzindo á escravidão econômica este país atrasado, o capital europeu liberava aos seus principais ramos da produção e aos seus principais meios de comunicação toda uma série de etapas técnicas e econômicas intermediárias, pelas quais eles tinham tido passar nos seus países de origem (LOWY, 1998, p. 74).

Esta origem estrangeira do capital industrial russo, segundo Trotsky, seria a causa da fraqueza da burguesia russa, e ao mesmo tempo, causa do peso político e social relativamente grande do proletariado urbano russo, concentrado em grandes unidades industriais modernas.

Se a ideia do desenvolvimento desigual e combinado é esboçada pela primeira vez no ensaio publicado em 1906 (Balanços e perspectivas), será justamente no livro 1905, publicado em 1909, onde a teoria será sustentada por um estudo mais detalhado e sistemático do desenvolvimento do capitalismo russo. Nesse sentido, a análise de Trotsky não se restringe aos aspectos econômicos do desenvolvimento. O revolucionário comunista passa a se atentar também aos aspectos sociais e culturais que permeiam a progressão do capitalismo na Rússia (LOWY, 1998).

Observando as contradições sociais da Rússia, Trotsky analisa que estão presentes

Todos os estágios da civilização: desde a selvageria primitiva das florestas setentrionais onde alimentavam-se de peixe cru e faziam suas preces diante de um pedaço de madeira, até as nova condições sociais da vida capitalista, onde o operário socialista se considera participante ativo da política mundial e segue atentamente... os debates do Reichstag (Trotsky, 1905, Apud. LOWY, 1998, p. 75).

Desta forma, é possível dizer que a indústria mais concentrada da Europa estava sobre bases de uma agricultura primitiva. E esses diferentes estágios não estão isolados um do outro, mas estão articulados, combinados e amalgamados. E o processo de desenvolvimento do capitalismo russo é justamente criado pela união dessas condições locais da Rússia, tidas como atrasadas, com as condições mais gerais, vistas como 
Pela revolução na periferia - notas introdutórias sobre a teoria do desenvolvimento desigual e combinado de Leon Trotsky. Revista Ensaios, vol. 14, jan-jun de 2019.

avançadas. Segundo Trotsky, essas condições históricas específicas só podem ser entendidas por meio de uma análise com bases materialistas.

Portanto, para compreender essa configuração social particular, é preciso partir do capital financeiro europeu - ou seja, do imperialismo, termo que Trotsky ainda não utilizada - que seria o principal vetor do desenvolvimento capitalista na Rússia. Nesse sentido, o capital na Rússia não percorre o mesmo itinerário dos países ocidentais. Ele "salta" algumas etapas intermediárias do seu crescimento "normal" e "orgânico", "como o pequeno ofício e a manufatura, e se manifesta imediatamente em sua figura mais moderna e avançada: a grande indústria” (LOWY, 1998, p.75).

Uma das questões paradoxais desse tipo específico de desenvolvimento do capitalismo periférico é que em certos aspectos, o capital estrangeiro implantado na periferia toma formas mais "avançadas" do que nas metrópoles. Trotsky, por exemplo, cita estatísticas comparativas mostrando a porcentagem de operários trabalhando em grandes fábricas no início do século XX. Enquanto na Alemanha a porcentagem de concentração era de $10 \%$, na Rússia era de 38,5 \%. É importante destacar que a análise teórica que Trotsky elabora com base no contexto russo, estava carregada implicitamente de uma significação muito mais abrangente, aplicável ao conjunto de diversas formas sociais situadas na periferia do sistema capitalista (LOWY, 1998, p. 76).

Segundo Michael Lowy (1998), é no primeiro capítulo da obra História da Revolução Russa - escrita em 1930 - que Trotsky formula enfim uma explicação explícita e coerente, ainda que breve, da teoria do desenvolvimento desigual e combinado. Para o sociólogo brasileiro, a hipótese de Trotsky que funda essa teoria pode ser formulada aproximadamente nos seguintes termos: com a transformação do capitalismo em um sistema global, a história mundial torna-se uma totalidade concreta e as condições do desenvolvimento social e econômico conhecem uma mudança significativa:

O capitalismo (...) preparou e, num certo sentido, realizou a universalidade e a permanência do desenvolvimento da humanidade. Por isto está excluída a possibilidade de uma repetição das formas de desenvolvimento de diversas nações. Forçado a se colocar a reboque dos países avançados, um país atrasado não se conforma com a ordem de sucessão (...) (TROTSKY, 1977, p. 24). 
Pela revolução na periferia - notas introdutórias sobre a teoria do desenvolvimento desigual e combinado de Leon Trotsky. Revista Ensaios, vol. 14, jan-jun de 2019.

Nesse sentido, as sociedades menos desenvolvidas acabam sendo obrigadas a adotar certos traços avançados, saltando as etapas intermediárias do sistema capitalista: "os selvagens renunciam ao arco e flecha, para logo tomarem os fuzis, sem percorrer a distância que os separava" (TROTSKY, 1977, p. 24). Desta forma, segundo Leon Trotsky, o desenvolvimento dos países atrasados passa por uma combinação original de diversidades, com um caráter irregular, complexo e combinado.

Lowy (1998) analisa que essa perspectiva mais complexa, que não é somente econômica, mas também cultural e política, permite a Trotsky escapar à concepção evolucionista do marxismo que via a história como uma sucessão mecânica e rígida de etapas pré-determinadas. Assim, Trotsky esboça uma visão e uma análise dialética do desenvolvimento histórico através de saltos súbitos e de fusões contraditórias:

\begin{abstract}
A desigualdade do ritmo, que é a lei mais geral do processo histórico, evidencia-se com maior vigor e complexidade nos destinos dos países atrasados. Sob o chicote das necessidades externas, a vida retardatária vê-se na contingência de avançar aos saltos. Desta lei universal da desigualdade dos ritmos decorre outra lei que, por falta de nominação apropriada, chamaremos de lei do desenvolvimento combinado, que significa aproximação das diversas etapas, combinação das fases diferenciadas, amálgama das formas arcaicas com as modernas (TROTSKY, 1977, p. 25).
\end{abstract}

O revolucionário russo afirma que a lei do desenvolvimento combinado se configura como a lei mais incontestável da história e principalmente no caráter da indústria russa. Desenvolvida tardiamente, essa indústria não percorre o mesmo itinerário dos países adiantados. Nela, as “conquistas modernas" se adaptam ao seu estado atrasado.

Uma das consequências desse tipo singular de desenvolvimento é o que se pode chamar de "privilégio dos retardatários". Ou seja, aqueles países que são considerados "atrasados" do ponto de vista de uma evolução história determinada, podem se tornar a vanguarda das transformações seguintes. Esse é o caso, por exemplo, segundo Trotsky, da Revolução Francesa. A França era um país no qual a reforma protestante teria "fracassado", e onde a igreja católica tinha permanecido hegemônica até o século XVIII. E mesmo assim, foi o primeiro país a realizar uma revolução não-religiosa em nome de princípios democráticos (LOWY, 1998). 
Pela revolução na periferia - notas introdutórias sobre a teoria do desenvolvimento desigual e combinado de Leon Trotsky. Revista Ensaios, vol. 14, jan-jun de 2019.

E a hipótese do "privilégio dos retardatários" é um dos pontos centrais do desenvolvimento teórico de Leon Trotsky. Ela implica claramente em uma ruptura metodológica com o economicismo tão característico do marxismo "ortodoxo". O ponto central é que a teoria elabora por Trotsky se distancia do eurocentrismo, admitindo a possibilidade de que os países periféricos se tornem vanguarda do movimento histórico.

Na perspectiva Trotskysta, o Estado Czarista possui um papel fundamental no desenvolvimento do capitalismo russo. Alvaro Bianchi (2001) analisa esse aspecto mostrando que as condições sob as quais a pressão externa foi exercida levaram o Estado Czarista a ser protagonista na constituição do capitalismo naquele país. Desta forma, o mercado mundial proporcionou o desenvolvimento do capitalismo na Rússia com a mediação do Estado. Nesse sentido, "o capitalismo russo aparece como filho do Estado" (BIANCHI, 2001, p. 104).

Baruch Kenei-Paz em seu texto Trotsky: Revolução permanente e revolução do atraso, também faz uma importante análise do papel do Estado no desenvolvimento do capitalismo russo. Segundo o autor polonês, Trostsky considerava a Rússia - partindo de um ponto de vista econômico, social e político - um país asiático. Porém, devido aos acontecimentos históricos, a geografia e a possibilidade de uma invasão dos países ocidentais mais desenvolvidos terminaram inserindo à Rússia na orbita de influência da política ocidental. Nesse sentido, a eminente possibilidade de invasões fez com que a Rússia precisasse reforçar e conservar sua própria independência. Ou seja, o Estado Czarista fora obrigado a adequar suas capacidades militares aos níveis dos países ocidentais. E uma das consequências desta situação geográfica e militar fez com que a Rússia modificasse seu plano econômico, mesmo que de forma indireta, na medida em que a tecnologia militar obrigava o Estado russo a construir uma infraestrutura industrial, ainda que embrionária.

Esse novo investimento industrial requeria fortes gastos públicos, os quais só se tornariam possível através de uma carga tributária extremamente onerosa para os camponeses, que seria a única fonte de renda produtiva para uma economia como a russa. Porém, os camponeses, já em condições de miséria, tornavam-se cada vez mais pobres e 
Pela revolução na periferia - notas introdutórias sobre a teoria do desenvolvimento desigual e combinado de Leon Trotsky. Revista Ensaios, vol. 14, jan-jun de 2019.

consequentemente o Estado russo acabou perdendo as principais fontes de produção das quais dependia (KENEI-PAZ, 1985).

Ao mesmo tempo, dentro desse processo, o Estado russo enfraquecia também as classes proprietárias, das quais, dependia financeiramente. Com o enfraquecimento econômico da propriedade da terra, o Estado dificultou o desenvolvimento econômico e produtivo dessas classes. Nesse sentido, na ausência de possibilidade de iniciativa independente, de desenvolvimento e acumulação, a grande propriedade ficava sob égide da autocracia russa. E isto constituía também um fator que limitava as classes proprietárias politicamente. Desta forma, limitada socialmente e economicamente, a burguesia russa não tinha condições de se opor á autocracia, assim como nas sociedades ocidentais (KENEI-PAZ, 1985).

A miserável condição dos camponeses, o enfraquecimento das classes proprietárias, e as exigências impostas à Rússia pela política ocidental na segunda metade do século XIX, obrigaram o império czarista a buscar investimentos e capital no exterior. Desta forma, acabou por forma uma espécie de "círculo vicioso": os empréstimos vindos da Europa ocasionaram uma pressão fiscal ainda mais pesada, que, por sua vez, empobreceu mais a população e impedia a criação de uma riqueza nacional independente.

Apesar desses fatores, Baruch Kenei-Paz (1985) argumenta que, no último quarto do século XIX o Estado russo lançou um programa de industrialização, com finalidade de impedir que a Rússia se tornasse uma colônia europeia e pudesse desenvolver uma economia que fosse, pelo menos em parte, moderna. Desse modo, a industrialização russa foi imposta pelo alto, pelo Estado.

O programa de industrialização teve um surpreendente sucesso, para além de qualquer expectativa, principalmente em termos tecnológicos, mostrando assim, a capacidade do poder estatal em adaptar o atraso russo com as inovações e transformações do setor produtivo e da vida social. É possível dizer que em alguns aspectos a Rússia não estava distante dos países ocidentais mais avançados. E disso resultou em um enorme crescimento da população urbana e, consequentemente, um aumento significativo da classe operária. 
Pela revolução na periferia - notas introdutórias sobre a teoria do desenvolvimento desigual e combinado de Leon Trotsky. Revista Ensaios, vol. 14, jan-jun de 2019.

Kenei-Paz (1985) aponta que a partir desse processo de desenvolvimento particular, Trotsky chega à conclusão de que a sociedade russa se encontrava em situação dramática de dilaceração, dividida em duas: por um lado, a enorme massa de população camponesa, em grande parte ainda não tocada pelos recentes desenvolvimentos; e, por outro, o novo setor industrial, "dotado de uma dinâmica interna própria e situado agora em fatal contraste com a primitiva organização política e social do Estado" (KENEI-PAZ, 1985, p. 175). E a anomalia desse estado de coisas revelava-se no fato de que as novas exigências da economia se encontravam em contraposição ao caráter e as possibilidades da estrutura social e política do país. Nesse sentido, apesar do fortalecimento do Estado em alguns aspectos, o próprio governo Czarista, de certa forma, acaba construindo as bases para sua própria derrota. Se antes havia conseguido controlar as medidas de modernização a ponto de resguardar a própria sobrevivência, agora o processo de transformação fez com que o Estado perdesse o controle. A revolução de 1905 foi um dos primeiros frutos dessa nova etapa do desenvolvimento russo.

Alvaro Bianchi (2001) analisa que a discussão sobre a maturidade da Rússia para a revolução socialista, que havia caracterizado o "marxismo legal" de Struve e o menchevismo de Plekanov, recebia de Trotsky uma formulação inovadora e extremamente poderosa: a maturidade para a revolução socialista não é definida pelo desenvolvimento nacional e sim da inserção da Rússia na economia mundial. Desta forma, as condições objetivas para a revolução eram definidas externamente à Rússia.

Nesse sentido, Bianchi (2001) argumenta que a teoria do desenvolvimento desigual e combinado é, na verdade, a teoria sobre o desenvolvimento do capitalismo em sua fase imperialista. Porém, o sociólogo brasileiro adverte que ao contrário de Lenin, Nicolai Bukharin e Rosa Luxemburgo não há em Trotsky uma obra propriamente econômica. Existiria sim uma teoria do imperialismo, presente de forma mais ou menos explícita em suas obras, mas não uma teoria econômica do imperialismo.

A teoria do imperialismo que perpassa a obra do marxista russo é, ao mesmo tempo, econômica e política. Segundo Bianchi (2001), a teoria coloca em seu centro a contradição fundamental existente entre o estado-nação e a internalização crescente das 
Pela revolução na periferia - notas introdutórias sobre a teoria do desenvolvimento desigual e combinado de Leon Trotsky. Revista Ensaios, vol. 14, jan-jun de 2019.

forças produtivas, transformando o mercado mundial em um elemento decisivo para a apreensão do imperialismo. Contradição essa que se manifesta, "por um lado nas contradições entre lei do valor no mercado mundial e a regulamentação estatal da economia no interior das fronteiras nacionais e, por outro, naquelas que existem entre os países imperialistas e os países coloniais e semicoloniais" (BIANCHI, 2001, p. 105-106).

Desta forma, existe uma dimensão política inerente ao conceito de imperialismo utilizado por Trotsky. Uma dimensão que está assentada na análise das contradições políticas, sociais, econômicas e ideológicas próprias do período imperialista. Para Bianchi (2001),

a teoria do desenvolvimento desigual e combinado permitiu a Trotsky pensar a unidade dialética existente entre economia e política situandose, imediatamente no nível da política e, mais especificamente, no nível da atualidade da revolução proletária (BIANCHI, 2001, p. 106).

Para Michael Lowy (1998), é uma infelicidade que após 1930 esse conjunto de hipóteses não tenham tido um desenvolvimento na obra de Trostsky. É espantoso até que ponto a teoria do desenvolvimento desigual e combinado é pouco presente nas reflexões do marxista russo sobre os países periféricos, senão como lembrança do precedente russo. Uma das exceções, segundo Lowy (1998), seria os escritos sobre a revolução republicana espanhola de 1931.

Segundo Ernest Mandel, a ideia do desenvolvimento desigual e combinado do capitalismo mundial é - com exceção da concepção de Marx sobre a determinação da luta de classes - a tese marxista amplamente assimilada desde há meio século, mesmo que raramente seja feita uma referência ao seu autor. E esta influencia foi exercida não somente no campo da economia política, mas também, no campo da história, sociologia e antropologia (LOWY, 1998).

Lowy (1998) aponta que, muitos trabalhos de sociólogos marxistas especialmente na Ásia e na América Latina - utilizam muitas vezes a teoria do desenvolvimento desigual e combinado, de forma explícita ou não, para tentar explicar e interpretar as particularidades das formações sociais em questão. 
Pela revolução na periferia - notas introdutórias sobre a teoria do desenvolvimento desigual e combinado de Leon Trotsky. Revista Ensaios, vol. 14, jan-jun de 2019.

Em relação à historiografia, é importante destacar o debate que durante muito tempo esteve no centro das controvérsias teóricas e políticas na América Latina, sobre a natureza capitalista ou semifeudal da economia colonial. Para Michael Lowy (1998), esse seria o melhor exemplo do impacto da teoria do desenvolvimento desigual e combinado nos próprios países periféricos.

A perspectiva tradicional dos Partidos Comunistas latino-americanos é representada pelo importante marxista uruguaio Rodney Arismendi, o qual defendia que as relações de produção introduzidas por Portugal e Espanha sobre o novo mundo eram feudais. Contrariando esse ponto de vista, outros eminentes pesquisadores marxistas, como o argentino Sergio Bagu, o brasileiro Caio Prado Jr e o chileno Marcelo Sagall, vão insistir nas dimensões capitalistas da colonização (LOWY, 1998).

Ernest Mandel (1995) irá defender a ideia de que dentre todos os socialistas que se destacaram no século XX, foi Trotsky que identificou com maior clareza as principais tendências do desenvolvimento e as principais contradições de sua época. E essa importância estaria enraizada, segundo Mandel, justamente em uma "descoberta teórica magnífica": a lei do desenvolvimento desigual e combinado. Mas apesar disso, é importante destacar que a importância de Trostky não é puramente sociológica. Mas essencialmente política. O comunista russo desenvolveu um conceito, ou modelo, "dos diferentes processos de lutas de classe numa escala global, e tirou disto as necessárias conclusões práticas, táticas, organizacionais e estratégicas” (MANDEL, 1995, p. 21). Portanto, os desenvolvimentos teóricos e práticos do revolucionário russo continuam sendo ferramentas indispensáveis para a análise da realidade concreta dos países periféricos, e imprescindíveis para qualquer perspectiva de transformação social.

\section{Referências:}

BIANCHI, Alvaro. "O primado da política: revolução permanente e transição" in

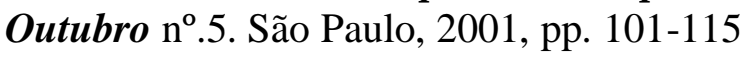

Trotsky em português: esboço bibliográfico. Campinas: IFCH/ Unicamp, 2005. (col. Textos didáticos, n. 54.) 
Pela revolução na periferia - notas introdutórias sobre a teoria do desenvolvimento desigual e combinado de Leon Trotsky. Revista Ensaios, vol. 14, jan-jun de 2019.

KNEI-PAZ, Baruch. "Trótski: revolução permanente e revolução do atraso" in HOBSBAWM, Eric J. (org.) História do marxismo $V$ (o marxismo na época da (Terceira Internacional: A Revolução de Outubro: $O$ autromarxismo). $2^{a}$ edição. Rio de Janeiro: Paz e Terra, 1985, pp. 159-196

LÖWY, Michael. "A teoria do desenvolvimento desigual e combinado" in Outubro, n. 1, 1998, p. 73-80.

TROTSKY, León. História da revolução russa. $2^{\mathrm{a}}$ edição. Rio de Janeiro: Paz e Terra, 1977.

Resultados Y perspectivas. Tres concepciones de la revolucion russa. Buenos Aires: El Yunque editora, 1975. 